OPEN ACCESS

Edited by:

Giorgio F. Gilestro,

Imperial College London,

United Kingdom

Reviewed by:

Fabian M. Feiguin,

International Centre for Genetic

Engineering and Biotechnology, Italy

Emi Nagoshi,

Université de Genève, Switzerland

*Correspondence:

Diana Pendin

diana.pendin@unipd.it

Specialty section:

This article was submitted to

Invertebrate Physiology,

a section of the journal

Frontiers in Physiology

Received: 04 June 2019 Accepted: 05 December 2019 Published: 20 December 2019

Citation:

Vajente $N$, Norante $R$, Redolfi $N$ Daga A, Pizzo P and Pendin D (2019) Microtubules Stabilization by Mutant Spastin Affects ER Morphology and

$\mathrm{Ca}^{2+}$ Handling

Front. Physiol. 10:1544.

doi: 10.3389/fphys.2019.01544

\section{Microtubules Stabilization by Mutant Spastin Affects ER Morphology and $\mathrm{Ca}^{2+}$ Handling}

\author{
Nicola Vajente ${ }^{1}$, Rosa Norante ${ }^{1}$, Nelly Redolfi ${ }^{1}$, Andrea Daga ${ }^{2}$, Paola Pizzo ${ }^{1,3}$ and \\ Diana Pendin ${ }^{1,3 *}$
}

1 Department of Biomedical Sciences, University of Padua, Padua, Italy, ${ }^{2}$ Laboratory of Molecular Biology, Scientific Institute IRCCS E. Medea, Lecco, Italy, ${ }^{3}$ Neuroscience Institute-Italian National Research Council (CNR), Padua, Italy

The endoplasmic reticulum (ER) extends as a network of interconnected tubules and sheet-like structures in eukaryotic cells. ER tubules dynamically change their morphology and position within the cells in response to physiological stimuli and these network rearrangements depend on the microtubule (MT) cytoskeleton. Store-operated calcium entry (SOCE) relies on the repositioning of ER tubules to form specific ER-plasma membrane junctions. Indeed, the tips of polymerizing MTs are supposed to provide the anchor for ER tubules to move toward the plasma membrane, however the precise role of the cytoskeleton during SOCE has not been conclusively clarified. Here we exploit an in vivo approach involving the manipulation of MT dynamics in Drosophila melanogaster by neuronal expression of a dominant-negative variant of the MT-severing protein spastin to induce MT hyper-stabilization. We show that MT stabilization alters ER morphology, favoring an enrichment in ER sheets at the expense of tubules. Stabilizing MTs has a negative impact on the process of SOCE and results in a reduced ER $\mathrm{Ca}^{2+}$ content, affecting the flight ability of the flies. Restoring proper MT organization by administering the MT-destabilizing drug vinblastine, chronically or acutely, rescues ER morphology, SOCE and flight ability, indicating that MT dynamics impairment is responsible for all the phenotypes observed.

Keywords: spastin, drosophila, microtubules, endoplasmic reticulum, calcium, SOCE, calcium imaging

\section{INTRODUCTION}

The endoplasmic reticulum (ER) coordinates a variety of cellular processes, such as synthesis, modification, quality control and transport of proteins, as well as lipid metabolism and $\mathrm{Ca}^{2+}$ homeostasis. It extends as a single membrane-bound entity composed of interconnecting sheets and tubules spreading all over the cell. Although the ER can form a reticular network independently of cytoskeletal structures (Dreier and Rapoport, 2000), in mammalian cells its distribution and sheet/tubule balance are influenced by microtubules (MTs) (Terasaki et al., 1986; Dabora and Sheetz, 1988; Lee and Chen, 1988; Waterman-Storer and Salmon, 1998; Lu et al., 2009; Joensuu et al., 2014).

MTs are composed of tubulin polymers and constitute essential components of the cytoskeleton. In neurons, they are critical in order to support long-range motor-driven cargo transport within neuronal processes and play fundamental roles in polarity, axon differentiation and growth (Conde and Cáceres, 2009; Kapitein and Hoogenraad, 2015). Although a part of the neuronal MTs is 
considered stable, a fraction retains high levels of dynamics, as demonstrated by their frequent and continuous growth and shortening (Desai and Mitchison, 1997; Nogales, 2001; Burbank and Mitchison, 2006). This dynamic instability is central to MT biological functions, allowing their rapid reorganization at need (Kirschner and Mitchison, 1986). The organization of MTs in neurons is tightly regulated by assembly-promoting factors, stabilizing and destabilizing factors and severing proteins. Dysfunctional MTs, due to mutations in genes that encode tubulin or MT-associated proteins, have been linked to a range of neuronal diseases, such as motor neuropathies, Hereditary Spastic Paraplegias (HSPs), Charcot-Marie-Tooth disease.

Two major types of MT-dependent ER movement have been described: sliding, the motor-based transfer along stable, preexisting MTs; and movement mediated by the tip attachment complex (TAC), by which a plus end-attached ER tubule extends together with a MT growing end (Waterman-Storer and Salmon, 1998; Friedman et al., 2010). TAC has been proposed to have a role in one of the major functions of $\mathrm{ER}$, i.e., intracellular $\mathrm{Ca}^{2+}$ handling. Indeed, the ER lumen contains a 10,000-fold higher $\mathrm{Ca}^{2+}$ concentration than that of the bulk cytosol, working as the primary intracellular $\mathrm{Ca}^{2+}$ store, releasing $\mathrm{Ca}^{2+}$ in the cytosol upon different cellular stimulations (Zampese and Pizzo, 2012; Pendin et al., 2017). The main source of $\mathrm{Ca}^{2+}$ for ER refilling is the extracellular space, and the plasma membrane (PM) is contacted by $\mathrm{ER}$ tubules in a process called store-operated $\mathrm{Ca}^{2+}$ entry (SOCE) (Várnai et al., 2009), which serves to generate a sustained cytosolic $\mathrm{Ca}^{2+}$ elevation and refill the depleted ER $\mathrm{Ca}^{2+}$ store.

The molecular players involved in SOCE include the poreforming subunit of the $\mathrm{Ca}^{2+}$-release activated $\mathrm{Ca}^{2+}$ channel encoded by the Orai gene (Feske et al., 2006; Prakriya et al., 2006; Vig et al., 2006a,b; Yeromin et al., 2006; Zhang et al., 2006) and the ER-resident protein STIM (stromal interaction molecule) (Liou et al., 2005; Zhang et al., 2005), that serves as a luminal $\mathrm{Ca}^{2+}$ sensor (Grigoriev et al., 2008; Friedman et al., 2010; Soboloff et al., 2012). It has been demonstrated that after $\mathrm{Ca}^{2+}$ store depletion, STIM oligomerizes and redistributes to predetermined foci in the peripheral ER (Luik et al., 2008). STIM binds the MT plus-end binding protein EB1, which facilitates TAC-dependent STIM translocation toward the PM (Liou et al., 2007; Honnappa et al., 2009; Chen et al., 2013, 2019; Tsai et al., 2014). At the ER-PM junctions, STIM interacts with Orai channels to promote influx of extracellular $\mathrm{Ca}^{2+}$ into the ER (Liou et al., 2007; Grigoriev et al., 2008; Galán et al., 2011). In this STIM redistribution process, the physical movement of ER is required for ER tubules to reach out to the PM and form new ERPM junctions (Wu et al., 2006; Carrasco and Meyer, 2011). The precise role of TAC-based ER movement in this reorganization, however, is controversial and variable among cell types (Redondo et al., 2006; Smyth et al., 2007; Grigoriev et al., 2008; Galán et al., 2011). One model proposes that TAC-mediated ER movement is required prior to SOCE activation to appropriately locate STIM on ER membrane, while ER $\mathrm{Ca}^{2+}$ depletion causes MTindependent STIM translocation to the PM (Smyth et al., 2007). Although the molecular details of this process are unclear, local cytoskeleton reorganization is supposed to play a major role (Gurel et al., 2014).

Spastin is an ATPase with MT-severing activity (Hazan et al., 1999; Errico et al., 2002; Roll-Mecak and McNally, 2010; Sharp and Ross, 2012; Sandate et al., 2019). Mutations in the spastin gene cause over $50 \%$ of cases of pure autosomal dominant HSPs, a group of neurodegenerative disorders characterized by lowerlimb spasticity and weakness (Fink, 2013); primarily due to degeneration of the descending axons of cortico-spinal neurons. Fly models for spastin-dependent HSP have been created both by inactivating protein function (Sherwood et al., 2004; Trotta et al., 2004) or by expressing a pathogenic mutant version of fly spastin (Orso et al., 2005). Despite the extensive progress in the comprehension of spastin functions, the specific mechanisms by which its mutants lead to HSPs remain unclear. Spastin has been implicated in axonal transport (Errico et al., 2002; Yu et al., 2008; Kasher et al., 2009; Fassier et al., 2013), neuromuscular junctions (NMJ) morphology and function (Sherwood et al., 2004; Trotta et al., 2004) and axon guidance (Wood et al., 2006; Butler et al., 2010), suggesting that its role in maintaining neuronal heath is likely related to its MT severing activity.

Here we show that MT alteration due to the expression of spastin carrying the pathogenic mutation K467R reduces SOCE and decreases ER $\mathrm{Ca}^{2+}$ content in Drosophila neurons. ER morphology appears altered, as an increase in ER sheets is observed at the expense of tubules. Importantly, both morphological and functional ER defects are rescued when flies are exposed to the MT-destabilizing drug vinblastine, indicating that rescue of MT structure is sufficient to restore ER normal shape and function.

\section{MATERIALS AND METHODS \\ Drosophila Stocks and Crosses}

The UAS-Dspastin-K467R and UAS-BiP-sf-GFP-ER fly lines used in this study were described previously (Orso et al., 2005; Summerville et al., 2016). The Gal4 strains used were: Elav-Gal4 (pan neuronal expression); D42-Gal4 (motor neurons restricted), obtained from Bloomington Drosophila Stock Center. To increase protein expression, all experimental crosses were performed at $28^{\circ} \mathrm{C}$. Control genotypes included promoterGal4/+ individuals. Fly food was prepared using NUTRI-flyIF mixture (Genesee Scientific), according to the manufacturer instructions. For chronic vinblastine treatment, NUTRI-fly-IF was additioned with $50 \mathrm{nM}$ vinblastine.

\section{Electron Microscopy}

Larval brains were fixed in $4 \%$ paraformaldehyde and $2 \%$ glutaraldehyde and embedded as previously described (Orso et al., 2009). Electron microscopy images were acquired from thin sections under a FEI Tecnai-12 electron microscope at the DeBio imaging Electron Microscopy Facility (University of Padova).

\section{Confocal Images of Larval Brains}

Brains and ventral ganglia from third instar larvae expressing BiP-sf-GFP-ER alone or together with spastin $^{\mathrm{K} 467 \mathrm{R}}$ were dissected in M1 medium (see below) containing $1 \mathrm{mM} \mathrm{Ca}^{2+}$, then 
motor neuron cell bodies were imaged on a Leica TCS SP5 II confocal microscope equipped with a HCX PL APO lambda blue 63x/1.40-0.60 Oil objective, using a $488 \mathrm{~nm}$ laser.

For the quantification of ER distribution along nerves, BiP-sfGFP-ER fluorescence was measured in regions located near the ganglion, along the axon, and at the end of the larval body. Mean fluorescence was calculated using ImageJ software.

\section{Protein Extraction and Western Blotting}

Proteins were extracted from 15 flies expressing BiP-sf-GFP-ER alone or together with spastin ${ }^{\mathrm{K} 467 \mathrm{R}}$ under the control of the motoneuron promoter D42-Gal4. GRS Full Sample Purification Kit (GRiSP, Lda.) was used according to the manufacturer's instructions. The protein pellet was solubilized in $80 \mu \mathrm{L}$ of RIPA Buffer (50 mM Tris, $150 \mathrm{mM} \mathrm{NaCl}, 1 \%$ Nonidet P-40, 0.5\% deoxycolic acid, $0.1 \%$ SDS, pH 7.5), supplemented with proteases and phosphatases inhibitors mixtures (Roche, 04693132001 and 04906837001) and $3 \mathrm{M}$ urea. Insoluble particles were spun down at $10,000 \mathrm{~g}$ for $5 \mathrm{~min}$. Proteins were separated by SDS-PAGE, transferred into nitrocellulose membranes (GE Healthcare, 10600001) and probed using the following antibodies: anti-GFP (Cell Signaling, 2956S), 1:1000; anti-ACT (beta-actin) (Sigma Aldrich, A2228), 1:2500. The intensity of the bands was analyzed using ImageJ software.

\section{Preparation of Larval Neurons}

Larval neurons were dissociated as previously reported (Chakraborty and Hasan, 2018). Briefly, third instar larvae were collected in a Petri dish, rinsed once with double-distilled water, twice with 70\% ethanol, then with M3 complete medium (Shields and Sang M3 Insect Medium, supplemented with 10\% heatinactivated FBS, $50 \mathrm{U} / \mathrm{mL}$ penicillin, $50 \mu \mathrm{g} / \mathrm{mL}$ streptomycin). Brains were dissected with sterilized forceps under a light microscope. Brains were washed twice with M3 complete medium, then transferred to an enzymatic solution $(0.75 \mu \mathrm{g} / \mu \mathrm{L}$ collagenase A and $0.4 \mu \mathrm{g} / \mu \mathrm{L}$ dispase II in M3 complete medium) and incubated for $20 \mathrm{~min}$ at room temperature in agitation. During incubation, brains were mechanically dissociated by gentle pipetting. Cell lysates were centrifuged at $600 \times \mathrm{g}$ for $5 \mathrm{~min}$ in a table top centrifuge and washed twice with dissecting solution to remove any residual enzymes. The cell pellet was resuspended with $100 \mu \mathrm{L}$ of M3 complete medium for each brain; $100 \mu \mathrm{L}$ were plated for each coverslip, approximately corresponding to one brain. Coverslips were previously autoclaved and coated with a drop of $0.1 \mathrm{mg} / \mathrm{mL}$ of poly-L-lysine for $30 \mathrm{~min}$ at $37^{\circ} \mathrm{C}$.

\section{Climbing Assay}

Climbing assay was performed as previously described (Agrawal and Hasan, 2015) using a $2.5 \mathrm{~cm}$ diameter glass cylinder. A group of 20 seven-days-old flies of the indicated genotype were dropped in the cylinder and a gentle taps were given to convey the flies to the bottom of the cylinder. The number of flies that crossed a mark drawn $10 \mathrm{~cm}$ above the bottom of the tube in a $60 \mathrm{~s}$ time window was counted manually. Each batch of flies was tested three times. The number of climbing flies for each batch was calculated as the mean of the climbing flies in the three repetitions. The total number of climbing flies for each genotype was calculated as the sum of the means. An independent proportion analysis was used to determine statistical differences between populations.

\section{Flight Assay}

The flight assay was adapted from a previously published protocol (Banerjee, 2004) using a $1 \mathrm{~m}$ long, Plexiglas cylinder (diameter $5 \mathrm{~cm}$ ) connected with an ethanol filled chamber at the bottom. Groups of 20 flies of a selected genotype were dropped into the cylinder through the top entry. A fly was determined to be capable of flight if it manages to reach the cylinder wall. Flies that could not perform this task fell directly to the ethanol filled chamber. Flight assays were performed on day 7 post eclosion. Data represent the percentage of flies capable of flight, at least 100 flies per condition were tested. Independent proportion analysis was used to determine the differences between groups.

\section{Cytosolic $\mathrm{Ca}^{2+}$ Imaging}

Neuronal cells were incubated with fura-2/AM $(1 \mu \mathrm{M})$, pluronic F-127 (0.02\%), and sulfinpyrazone $(200 \mu \mathrm{M})$ for $20 \mathrm{~min}$ at room temperature (RT) in a M1 buffer (see below) and then in a fresh solution without the $\mathrm{Ca}^{2+}$ indicator for $20 \mathrm{~min}$ at RT. Fura-2-loaded cells were visualized with a $20 \mathrm{x}$ ultravioletpermeable objective (CFI Sfluor 20x N.A. 0.75, Nikon) on an inverted microscope (Nikon Ti-E). Fluorescence illumination was achieved by 50-75W Lamp (USHIO UXLS50A) and alternating excitation wavelengths $(340 / 380 \mathrm{~nm})$ were obtained by a monochromator (Optoscan CAIRN-Research) controlled by NIS-ELEMENTS AR (Nikon) software. A neutral density filter, ND4 (Nikon, USA) and a FF-409-DiO3 Dichroic (Semrock) were used in the excitation pathway. The emitted fluorescence was collected using a 510/84 nm (Semrock) filter. Images were acquired every $1 \mathrm{~s}$, with $100 \mathrm{~ms}$ exposure time at each wavelength, by a Zyla-CMOS 4.2-P (Andor, Oxford Instruments) controlled by the same software. During the experiment, cells plated on coverslips were mounted into an open-topped chamber and maintained in an extracellular-like medium containing the following:

(1) M1 ( $\mathrm{Na}^{+}$-based) medium: $30 \mathrm{mM}$ HEPES, $150 \mathrm{mM} \mathrm{NaCl}$, $5 \mathrm{mM} \mathrm{KCl}, 1 \mathrm{mM} \mathrm{MgCl} 2,35 \mathrm{mM}$ sucrose, 5 glucose, $\mathrm{pH} 7.2$ with $\mathrm{NaOH}$ at RT;

(2) $\mathrm{K}^{+}$-based medium: $30 \mathrm{mM}$ HEPES, $145 \mathrm{mM}$ K-Dgluconate, $10 \mathrm{mM} \mathrm{NaCl}, 1 \mathrm{mM} \mathrm{MgCl}_{2}, 35 \mathrm{mM}$ sucrose, $5 \mathrm{mM}$ glucose $\mathrm{pH} 7.2$ with $\mathrm{KOH}$ at RT.

For store $\mathrm{Ca}^{2+}$ content evaluation, cells were firstly perfused with M1 containing $1 \mathrm{mM} \mathrm{CaCl}_{2}$; after addition of $500 \mu \mathrm{M}$ EGTA, cells were stimulated by addition of ionomycin $(10 \mu \mathrm{M})$ or cyclopiazonic acid (CPA, $50 \mu \mathrm{M})$. In the second case, for residual $\mathrm{Ca}^{2+}$ evaluation, cells were further stimulated with addition of ionomycin $(10 \mu \mathrm{M})$. For SOCE activation experiments, cells were pre-treated with the irreversible SERCA inhibitor thapsigargin $(100 \mathrm{nM})$ for $10 \mathrm{~min}$ in a $\mathrm{Ca}^{2+}$-free, EGTA $(500 \mu \mathrm{M})$-containing M1; cells were then perfused with the same medium without the SERCA inhibitor and challenged with $\mathrm{CaCl}_{2}(2$ or $5 \mathrm{mM})$. Where indicated, $\mathrm{M} 1\left(\mathrm{Na}^{+}\right.$-based) medium was substituted with $\mathrm{K}^{+}$-based medium. 
For acute vinblastine treatment, the drug $(1 \mu \mathrm{M})$ was added in each solution and step of the experimental protocol, from fura-2/AM cell loading to cell stimulations. Neurons dissociated from larvae exposed to chronic vinblastine treatment, were similarly treated.

\section{$\mathrm{Ca}^{2+}$ Imaging Experiments Analysis}

Off-line analysis of $\mathrm{Ca}^{2+}$ imaging experiments was performed using the NIS-Elements software. $F_{340}$ and $F_{380}$ images were subtracted of background signals and proper regions of interest (ROIs) were selected on each imaged cell. The ratio of the emitted fluorescence intensities $\left(\mathrm{R}=\mathrm{F}_{340} / \mathrm{F}_{380}\right)$ was calculated for each ROI, normalized to the value measured before stimulus addition, or at the $\mathrm{Ca}^{2+}$-free status, and averaged offline. Data were analyzed using Microsoft Excel and Graphpad Prism 8 to calculate areas under the curves (AUC).

\section{Statistical Analyses}

Fura-2 traces represent average values of 100 to 1,000 cells collected in 3-10 independent experiments. Average values are expressed as mean \pm standard error of the mean ( $n=$ number of cells, unless otherwise specified). Statistical analyses were

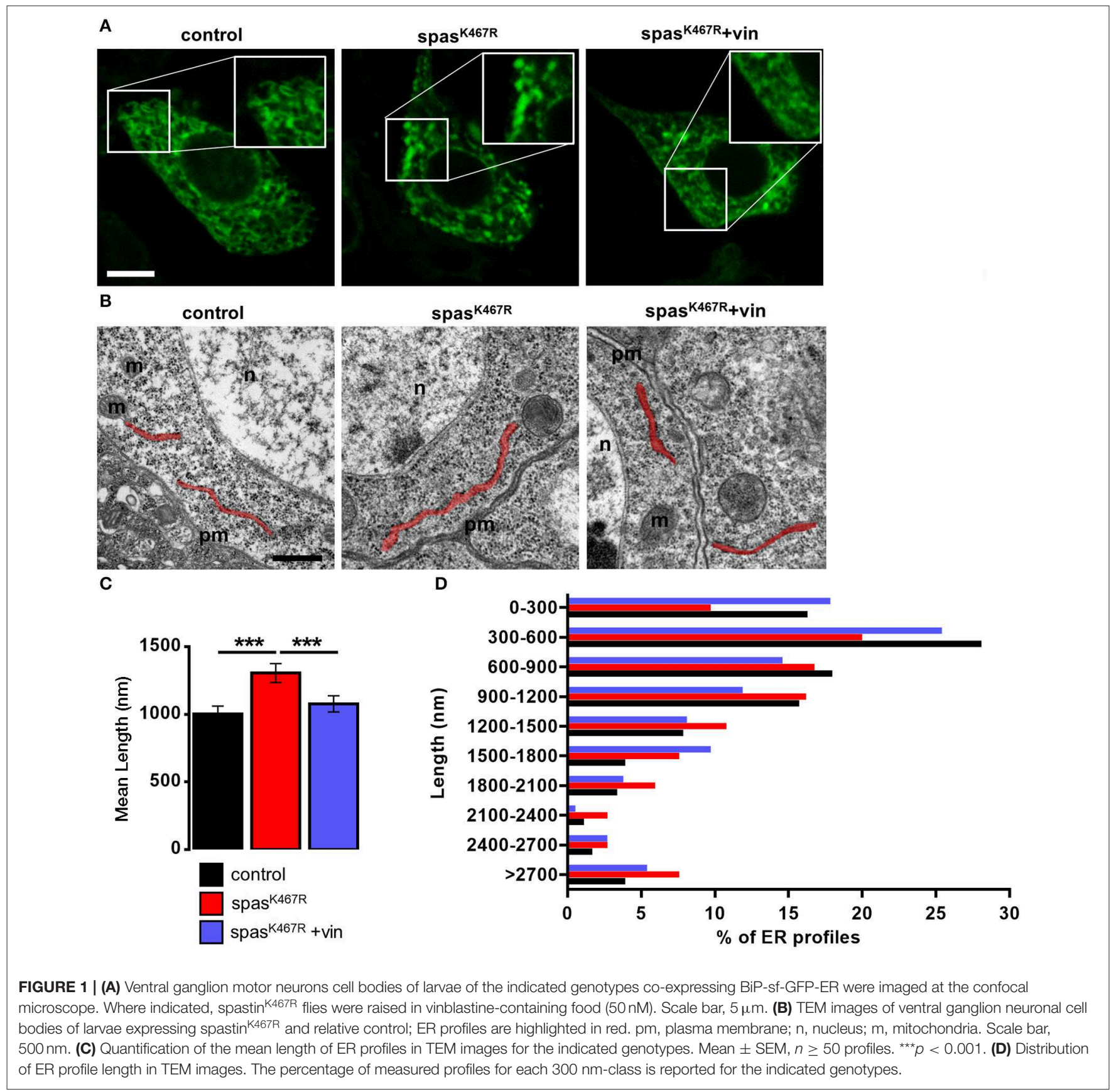


performed using unpaired Student's t-test. Analyses of differences between fly populations were made using chi-square independent proportion analysis. Both tests were applied with a confidence interval of $95 \%\left({ }^{*} p<0.05,{ }^{* *} p<0.01,{ }^{* * *} p<0.001\right)$.

\section{Materials}

Shields and Sang M3 Insect Medium, Dispase II, vinblastine, thapsigargin, EGTA and $\mathrm{CaCl}_{2}$ were purchased from SigmaAldrich. CPA, and ionomycin were purchased from Abcam, Collagenase A was purchased from Roche. Fura-2/AM was purchased from Thermo Fisher. All other materials were analytical or of the highest available grade.

\section{RESULTS}

\section{Neuronal Expression of Spastin ${ }^{\mathrm{K} 467 R}$ Influences ER Morphology}

To alter MT stability, we used a transgenic line for the expression of Drosophila spastin carrying the mutation K467R under the control of UAS promoter (UAS-Dspastin-K467R). The amino acid substitution, located in the AAA ATPase domain, corresponds to the pathogenic mutation K388R in the human spastin protein, known to produce a dominant-negative effect (Orso et al., 2005). Indeed, when spastin ${ }^{\mathrm{K} 467 \mathrm{R}}$ is expressed in a wild-type background, hyper-stabilization of MTs has been observed, similar to that produced by downregulation of spastin (Orso et al., 2005). We expressed spastin ${ }^{\mathrm{K} 467 \mathrm{R}}$ in the fly nervous system, using the pan-neuronal driver elav-Gal4. The birth rate of flies expressing spastin ${ }^{\mathrm{K} 467 \mathrm{R}}$ was partially reduced, compared to control flies (Supplementary Figure 1A). Moreover, we confirmed that these flies show a shorter lifespan and locomotor dysfunction (Supplementary Figures 1B,C), as previously reported (Orso et al., 2005).

Because MTs are known to regulate ER distribution and sheet/tubule balance (Terasaki et al., 1986; Lu et al., 2009), we examined ER morphology in fly neurons expressing spastin $^{\mathrm{K} 467 \mathrm{R}}$. To visualize ER structure, we co-expressed the ER luminal marker BiP-sfGFP-HDEL (Summerville et al., 2016) under the control of the motoneuron-specific promoter D42-Gal4. In control motor neuron cell bodies, the ER appears mostly as a network of interconnected tubules (Figure 1A). In motor neurons expressing spastin ${ }^{\mathrm{K} 467 \mathrm{R}}$, ER morphology was markedly changed and extended fluorescent areas, likely representing ER sheets, were often present (Figure 1A, Supplementary Videos 1-3). Axons are believed to contain mainly tubular, smooth ER that tracks to axon termini (Tsukita and Ishikawa, 1976; Terasaki and Reese, 1994; Krijnse-Locker et al., 1995; Terasaki, 2018). Moving along the longest motor neurons from the cell body to the axon termini, the density of ER only slightly decreases in control larvae (Supplementary Figures 2A,B). In contrast, in larvae expressing spastin ${ }^{\mathrm{K} 467 \mathrm{R}}$, distal axons appear almost devoid of ER (Supplementary Figures 2A,B). This phenotype, although consistent with an impairment of axonal transport of ER tubules, could be also the result of a decrease in ER tubules amount. Noteworthy, western blotting analysis of $\mathrm{BiP}-$ sfGFP-HDEL amount in individuals expressing spastin ${ }^{\mathrm{K} 467 \mathrm{R}}$ or in controls indicated that the morphological alterations observed in cell bodies and axons does not affect total ER mass (Supplementary Figures 2C,D). To investigate in more depth the morphological change observed, we performed transmission electron microscopy (TEM) analysis of larval brains. The length of ER profiles measured in TEM thin sections, corresponding to a cut through sheet-like structures, reflects the organization of the ER (Puhka et al., 2012): a shift to longer profiles corresponds to an increase in sheets vs tubules ratio. The analysis of TEM thin sections revealed an increase in the length of ER profiles in spastin ${ }^{\mathrm{K} 467 \mathrm{R}}$-expressing neurons, compared to controls (Figures 1B,C). In particular, the relative abundance of profiles of the shortest classes $(0-300 \mathrm{~nm}$ and $300-600 \mathrm{~nm})$ is decreased in spastin ${ }^{\mathrm{K} 467 \mathrm{R}}$ expressing neurons, while an increase in profiles longer than $2 \mu \mathrm{m}$ is evident (Figure 1D). This is consistent with an increase in ER sheets compared to tubules.

Altogether, these results suggest that the expression of a dominant-negative spastin mutant leads preferentially to the formation of ER sheets to the detriment of tubules.

\section{Neuronal Expression of Spastin ${ }^{\mathrm{K} 467 R}$ Affects ER $\mathrm{Ca}^{2+}$ Handling}

We reasoned that such morphological changes would have an impact on definite ER functions that depend very much on the presence of tubular ER. Specifically, TAC-mediated movement of ER tubules is believed to be directly involved in SOCE activation, the process necessary to refill depleted $\mathrm{ER} \mathrm{Ca}^{2+}$ stores. In order to investigate the impact of spastin ${ }^{\mathrm{K} 467 \mathrm{R}}$ expression on ER $\mathrm{Ca}^{2+}$ dynamics, and specifically on SOCE, neurons were isolated from larval brains expressing spastin ${ }^{\mathrm{K} 467 \mathrm{R}}$ under the control of a pan-neuronal promoter (elav-Gal4/UAS-spastin ${ }^{\mathrm{K} 467 \mathrm{R}}$ ), or from controls (elav-Gal4/+) (Supplementary Figure 3), loaded with the $\mathrm{Ca}^{2+}$ indicator fura- 2 and examined by fluorescence microscopy. A typical protocol to elicit SOCE was applied to neurons: store depletion was induced by adding the SERCA inhibitor thapsigargin in a $\mathrm{Ca}^{2+}$-free medium; SOCE was then monitored upon $\mathrm{CaCl}_{2}$ addition $\left(\mathrm{Ca}^{2+}, 2 \mathrm{mM}\right)$. A large cytosolic $\mathrm{Ca}^{2+}$ concentration $\left(\left[\mathrm{Ca}^{2+}\right]_{\mathrm{c}}\right)$ increase, followed by a sustained plateau, due to $\mathrm{Ca}^{2+}$ influx across the $\mathrm{PM}$, was observed in control neurons (Figure 2A). The effect of spastin mutation on the $\mathrm{Ca}^{2+}$ influx activated by store depletion was quantified by calculating the area under the curve corresponding to the first 2 min of $\mathrm{Ca}^{2+}$ influx. A marked decrease in SOCE was observed in neurons from larvae expressing spastin ${ }^{\mathrm{K} 467 \mathrm{R}}$, compared to controls (37\% reduction, $p<0.001 ; n=350$ control cells; $n=$ 300 spastin $^{\mathrm{K} 467 \mathrm{R}}$ cells; Figure 2B).

It is known that differences in PM potential alter the driving force for $\mathrm{Ca}^{2+}$ entry, thus potentially affecting the extent of SOCE (Penner et al., 1993). To nullify possible differences in membrane potential between the two genotypes, SOCE was measured as described above but in a medium where $\mathrm{NaCl}$ was isoosmotically substituted by potassium- $\mathrm{D}$-gluconate $\left(\mathrm{K}^{+}\right.$-based medium, see Methods for details), causing the collapse of the membrane potential. A higher concentration of $\mathrm{CaCl}_{2}(5 \mathrm{mM})$ was applied, after emptying stores, to obtain an appreciable $\mathrm{Ca}^{2+}$ influx even under a reduced electrical gradient. Under such 


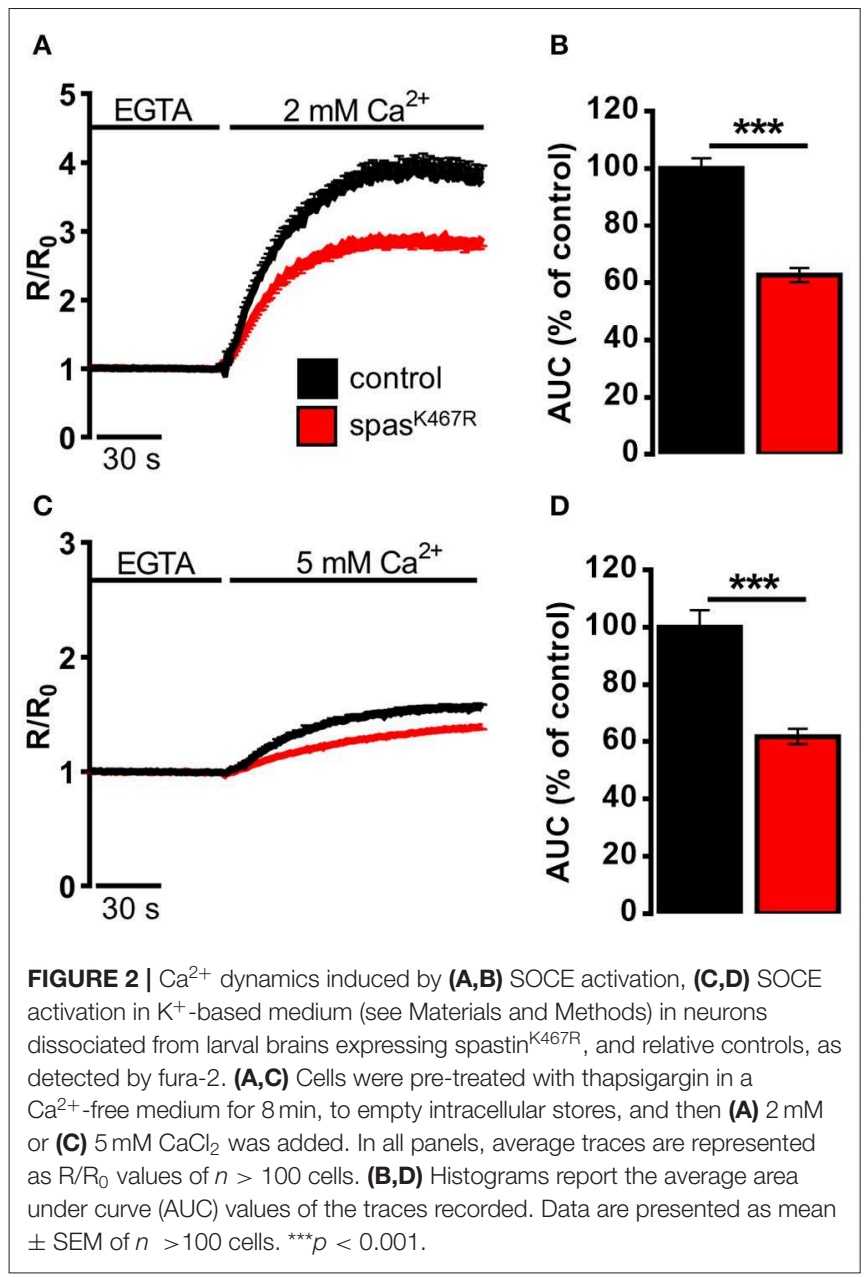

depolarizing conditions, the effect of spastin $^{\mathrm{K} 467 \mathrm{R}}$ expression on SOCE was similar to that found in the standard $\mathrm{Na}^{+}$-containing medium (38\% reduction, $p<0.001 ; n=300$ control cells; $n$ $=280$ spastin $^{\mathrm{K} 467 \mathrm{R}}$ cells; Figures 2C,D). When basal SOCE was measured in the same cells, by simply adding back $\mathrm{Ca}^{2+}$ to cells bathed in a $\mathrm{Ca}^{2+}$-free medium, no difference was found between the two genotypes, neither in standard medium nor in $\mathrm{K}^{+}$-based medium (Supplementary Figures 4A-D).

The decrease in $\mathrm{Ca}^{2+}$ entry upon store depletion could cause a partial depletion of intracellular $\mathrm{Ca}^{2+}$ stores in spastin ${ }^{\mathrm{K} 467 \mathrm{R}}$ expressing neurons. To investigate this possibility, the $\mathrm{Ca}^{2+}$ ionophore ionomycin was applied to neurons bathed in a $\mathrm{Ca}^{2+}$-free medium containing the $\mathrm{Ca}^{2+}$ chelator EGTA. In this situation, the rise observed in $\left[\mathrm{Ca}^{2+}\right]_{c}$ is due to the discharge of the majority of intracellular $\mathrm{Ca}^{2+}$ store pools (Figure 3A). The increase in $\left[\mathrm{Ca}^{2+}\right]_{c}$ elicited by ionomycin was significantly reduced in spastin ${ }^{\mathrm{K} 467 \mathrm{R}}$ expressing neurons, relative to controls, as indicated by the area under the curve obtained upon ionomycin addition (22\% reduction, $p<0.001$; $n=90$ control cells; $n=100$ spastin $^{\mathrm{K} 467 \mathrm{R}}$ cells; Figure $\left.3 \mathbf{B}\right)$. A subsequent addition of monensin, in order to discharge any residual $\mathrm{Ca}^{2+}$ present in the acidic pool (Fasolato et al., 1991), did
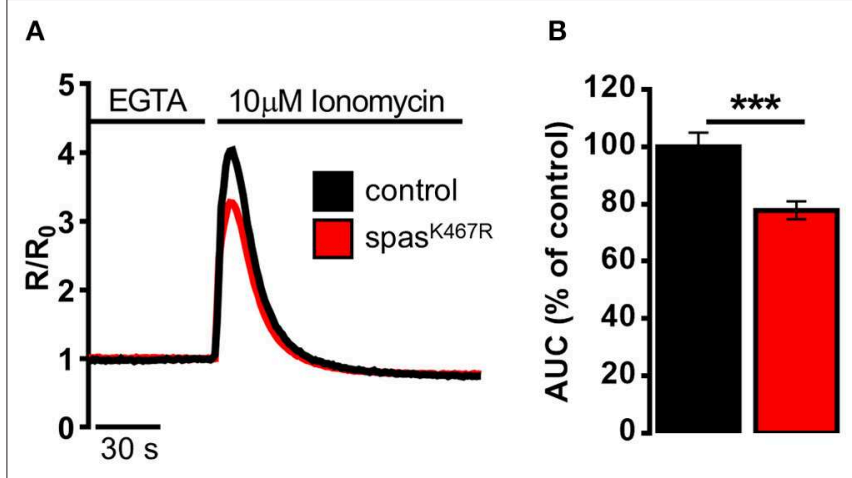

C

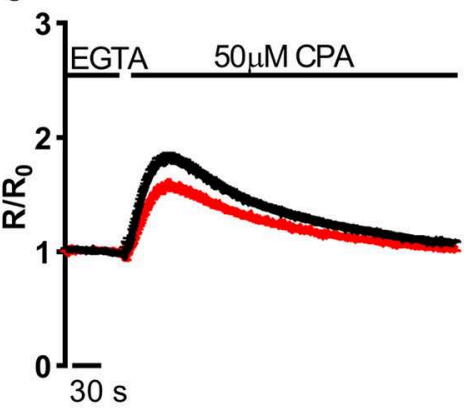

D

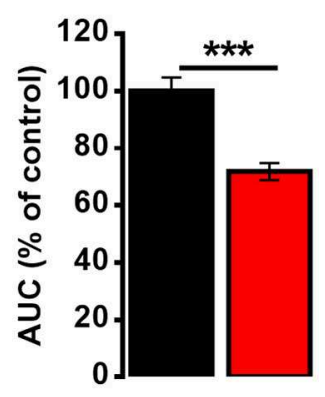

E

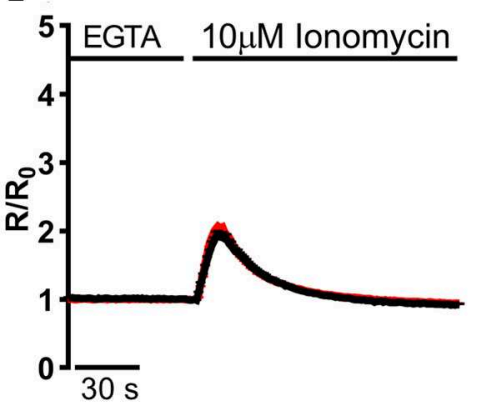

$\mathbf{F}$

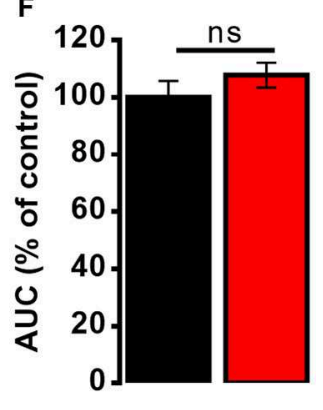

FIGURE 3 | $\mathrm{Ca}^{2+}$ dynamics induced by (A,B) ionomycin, (C,D) CPA, (E,F) ionomycin after CPA-induced ER depletion in neurons dissociated from larval brains expressing spastin ${ }^{\mathrm{K} 467 \mathrm{R}}$, and relative controls, detected by fura-2. (A,C,E) Cells were stimulated with (A,E) $10 \mu \mathrm{M}$ ionomycin or (C) $50 \mu \mathrm{M}$ CPA in the presence of extracellular $\mathrm{Ca}^{2+}$ chelator EGTA. In all panels, average traces are represented as $\mathrm{R} / \mathrm{R}_{0}$ values of $n>100$ cells. (B,D,F) Histograms report the average area under curve (AUC) values of the traces recorded. Data are presented as mean \pm SEM of $n>100$ cells. ${ }^{* \star *} p<0.001$.

not result in an appreciable $\left[\mathrm{Ca}^{2+}\right]_{\mathrm{c}}$ increase in either genotypes (data not shown), indicating the relative low abundance of this type of $\mathrm{Ca}^{2+}$ stores in these cells. This result indicates that $\mathrm{Ca}^{2+}$ content of intracellular stores is diminished in cells expressing the spastin ${ }^{\mathrm{K} 467 \mathrm{R}}$ mutation. To determine whether the observed reduction was due to a specific partial depletion of the $\mathrm{ER} \mathrm{Ca}^{2+}$ store, dissociated neurons were treated with the SERCA inhibitor CPA, thus inducing the passive release of $\mathrm{Ca}^{2+}$ from the organelle, resulting in a transient increase in $\left[\mathrm{Ca}^{2+}\right]_{\mathrm{c}}$ (Figure 3C). The amplitude of the increase in $\left[\mathrm{Ca}^{2+}\right]_{\mathrm{c}}$ reflects the $\mathrm{Ca}^{2+}$ content derived only from the ER and the cis/medial-Golgi, the main intracellular $\mathrm{Ca}^{2+}$ stores equipped 

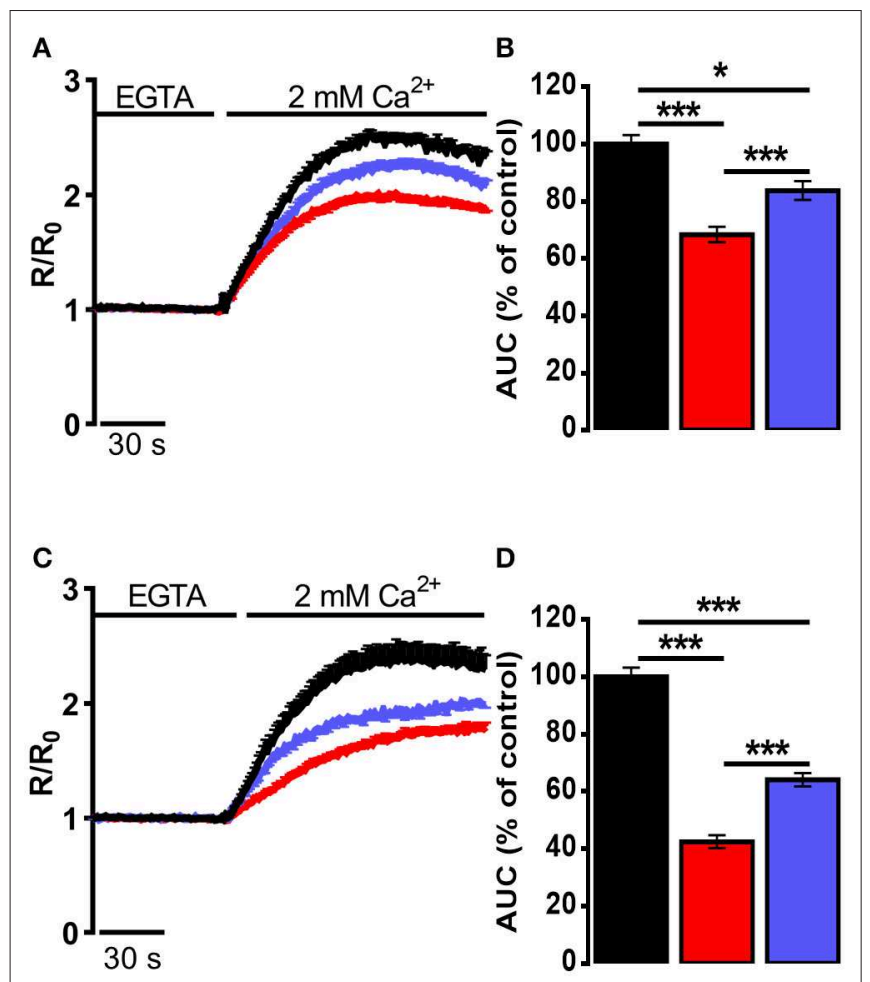

E

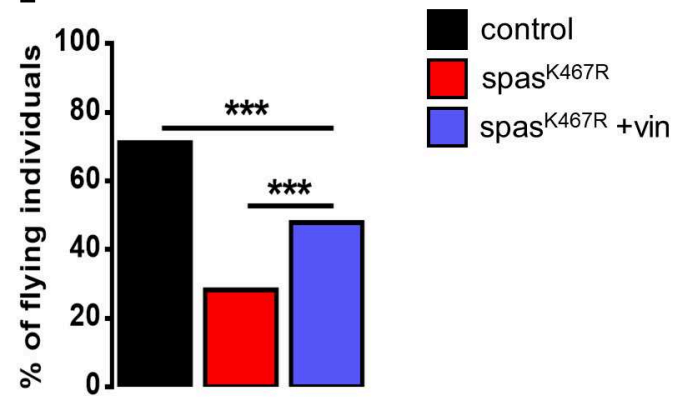

FIGURE 4 | (A-D) $\mathrm{Ca}^{2+}$ dynamics induced by SOCE activation in neurons dissociated from larval brains expressing spastin ${ }^{\mathrm{K} 467 \mathrm{R}}$, and relative control, as detected by fura-2. Were indicated, vinblastine was applied: $(\mathbf{A}, \mathbf{B})$ during development, larvae were chronically treated with $50 \mathrm{nM}$ vinblastine or $(\mathbf{C , D})$ after dissociation, neurons were acutely treated with $1 \mu \mathrm{M}$ vinblastine. Cells were pre-treated with thapsigargin for 8 min to empty intracellular stores, then $2 \mathrm{mM} \mathrm{CaCl}_{2}$ was added. Traces are presented as average R/Ro values of $n>$ 100 cells. (B,D) Histograms reporting the average area under curve (AUC) values of the corresponding traces. Data are presented as mean \pm SEM of $n$ $>100$ cells. ${ }^{*} p<0.05 ;{ }^{* \star} p<0.001$. (E) Flight ability, assayed by the cylinder drop test, of animals expressing spastin ${ }^{\mathrm{K} 467 \mathrm{R}}$ and relative control. Where indicated, animals were chronically exposed to vinblastine $(50 \mathrm{nM})$. Data are presented as the percentage of flying individuals. Mean of $n>100$ cells. ${ }^{* \star} p$ $<0.001$.

with SERCA pumps (Lissandron et al., 2010; Wong et al., 2013). The increase in $\left[\mathrm{Ca}^{2+}\right]_{c}$ elicited by CPA was significantly reduced in spastin ${ }^{\mathrm{K} 467 \mathrm{R}_{-}}$-expressing neurons, relative to controls (Figure 3C). The extent of such reduction, estimated calculating the area under the curve above resting $\left[\mathrm{Ca}^{2+}\right]_{c}$ values, was $28 \%\left(p<0.001 ; n=220\right.$ control cells; $n=160$ spastin $^{\mathrm{K} 467 \mathrm{R}}$ cells; Figure 3D). Thus, ER $\mathrm{Ca}^{2+}$ content is diminished in cells expressing the spastin ${ }^{\mathrm{K} 467 \mathrm{R}}$ mutation. After CPA application, the discharge of residual $\mathrm{Ca}^{2+}$ pools, by ionomycin addition, did not show any differences between control and spastin ${ }^{\mathrm{K} 467 \mathrm{R}_{-}}$ expressing neurons (Figures 3E,F), indicating that the $\left[\mathrm{Ca}^{2+}\right]_{E R}$ is primarily affected by spastin mutation. Of note, basal $\left[\mathrm{Ca}^{2+}\right]_{\mathrm{c}}$ content is not affected (Supplementary Figure 4E). Altogether, these data indicate that expression of $\operatorname{spastin}^{\mathrm{K} 467 \mathrm{R}}$ causes an impairment of the ER $\mathrm{Ca}^{2+}$ replenishment mechanism of SOCE. This likely results in a reduction of the steady-state $\left[\mathrm{Ca}^{2+}\right]_{\mathrm{ER}}$.

\section{Vinblastine Treatment Rescues ER Morphology and $\mathrm{Ca}^{2+}$ Handling Defects Induced by Spastin ${ }^{\mathrm{K} 467 \mathrm{R}}$ Expression}

In order to assess whether MT cytoskeleton impairment was directly responsible for ER morphology and $\mathrm{Ca}^{2+}$ handling defects observed in spastin ${ }^{\mathrm{K} 467 \mathrm{R}}$-expressing flies, and to exclude other possible effects of mutant spastin expression, we exploited a pharmacological approach. It has been shown that administration of low concentrations of the MT-targeting drug vinblastine rescued the excessive stabilization of MTs in spastin ${ }^{\mathrm{K} 467 \mathrm{R}}$-expressing flies (Orso et al., 2005). We thus administered vinblastine to control and spastin ${ }^{\mathrm{K} 467 \mathrm{R}}$ flies by adding the drug to the food at a concentration of $50 \mathrm{nM}$ (Orso et al., 2005). When we examined the fluorescence of the ER marker BiP-sfGFP-HDEL (Summerville et al., 2016), we found that exposure to the MT-targeting drug resulted in recovery of ER morphology in flies expressing spastin ${ }^{\mathrm{K} 467 \mathrm{R}}$ (Figure 1A). The rescue is confirmed also by the quantification of ER profiles length in TEM thin sections (Figures 1B,C). Moreover, in neurons dissociated from brains of the same larvae, we evaluated SOCE, as described above. We found that the reduction in the $\mathrm{Ca}^{2+}$ entry following stores depletion, observed in neurons derived from larvae expressing spastin ${ }^{\mathrm{K} 467 \mathrm{R}}$, was partially recovered by vinblastine treatment (Figures $4 A, B$ ), indicating that the drug-induced destabilization of hyper-stabilized MTs rescues the spastin ${ }^{\mathrm{K} 467 \mathrm{R}}$-induced SOCE defects.

It has been shown that loss of MT polymers in response to vinblastine occurs very rapidly, starting in as little as $30 \mathrm{~min}$ (Harkcom et al., 2014). In order to further demonstrate that the rescue of MT cytoskeleton is directly responsible for the recovery of SOCE impairment observed in spastin ${ }^{\mathrm{K} 467 \mathrm{R}}$-expressing flies, we acutely applied vinblastine $(1 \mu \mathrm{M})$ on neurons dissociated from spastin ${ }^{\mathrm{K} 467 \mathrm{R}}$ larvae raised in the absence of drug in the food. Application of vinblastine for $40 \mathrm{~min}$ before SOCE activation and visualization was able to induce a partial rescue in the extent of $\mathrm{Ca}^{2+}$ entry, compared to untreated spastin ${ }^{\mathrm{K} 467 \mathrm{R}_{-}}$ expressing neurons (Figures 4C,D). This result indicates that reestablishment of proper MT organization is sufficient to rescue the process of $\mathrm{Ca}^{2+}$ entry upon stores depletion, affected by the spastin mutant.

Pan-neural downregulation of dStim or dOrai leads to a significant reduction of SOCE and $\mathrm{ER}\left[\mathrm{Ca}^{2+}\right]$ in primary neuronal cultures (Venkiteswaran and Hasan, 2009). Reduced SOCE has been shown to affect fly neuronal functions, in particular a significant loss of flight has been observed. In order 
to assess whether the defect in SOCE observed upon spastin ${ }^{\mathrm{K} 467 \mathrm{R}}$ expression was also associated with an impairment in flight, we performed the "cylinder drop" test assay, which revealed a defect in the flight ability of spastin ${ }^{\mathrm{K} 467 \mathrm{R}}$-expressing flies $(42 \%$ reduction of spastin ${ }^{\mathrm{K} 467 \mathrm{R}}$ compared to control, $p<0.001 ; n=$ 100 control cells; $n=100$ spastin $^{\mathrm{K} 467 \mathrm{R}}$ cells; Figure 4E). This defect was partially rescued when flies were raised in vinblastinecontaining food (Figure 4E).

\section{DISCUSSION}

$\mathrm{Ca}^{2+}$ signals regulate fundamental aspects of neuronal function and physiology and contribute in determining the morphology of neural circuits (Berridge, 1998; Borodinsky and Spitzer, 2007). Traditionally, most of these signals were attributed to the entry of $\mathrm{Ca}^{2+}$ from the extracellular milieu through voltageoperated channels or ionotropic receptors. However, the " $\mathrm{Ca}^{2+}$ toolkit" components related to $\mathrm{Ca}^{2+}$ release from intracellular stores are also present in neurons. Increasing evidence suggests that also neurons rely on SOCE and its dysregulation may participate in the pathogenesis of diverse neurodegenerative diseases, such as Alzheimer's, Parkinson's, Charcot-Marie-Tooth (Secondo et al., 2018).

The aim of this study was to determine the influence of neuronal MT cytoskeleton architecture on the process of SOCE, the opening of $\mathrm{PM} \mathrm{Ca}{ }^{2+}$ channels that follows the release of $\mathrm{Ca}^{2+}$ from intracellular stores. The molecular mechanism of cytoskeleton regulation over the relocation of STIM to ERPM junctions during SOCE is not fully understood. It appears clear that coordinated interplay between different molecules is necessary to mediate the transient formation of ER-PM junctions (Grigoriev et al., 2008; Sharma et al., 2013; Maléth et al., 2014; Woo et al., 2016), but whether the integrity of cytoskeleton is needed for proper SOCE activation is not clear. Opposing data are present in literature, suggesting both inhibition (Oka et al., 2005; Smyth et al., 2007) or potentiation (Galán et al., 2011) of SOCE in the presence of MT-depolymerizing agents (Russa et al., 2009; Martin-Romero et al., 2017). To sort this out, we performed an in vivo approach in Drosophila melanogaster exploiting an endogenous means to manipulate MT dynamic instability. We expressed in Drosophila a variant of the MT-severing protein spastin carrying an amino acid substitution known to function as a dominant-negative, thus inducing MT hyper-stabilization. Our results clearly indicate that the process of $\mathrm{Ca}^{2+}$ entry upon $\mathrm{ER} \mathrm{Ca}^{2+}$ depletion is negatively affected by MT stabilization. This impairment results in a reduced $\mathrm{ER} \mathrm{Ca}^{2+}$ content without, however, affecting cytosolic basal $\mathrm{Ca}^{2+}$ levels.

The phenotypes we observed upon neuronal expression of spastin $^{\mathrm{K} 467 \mathrm{R}}$ recapitulate those observed upon dStim or dOrai reduction in flies. Pan-neural downregulation of dStim or dOrai leads to a significant decrease in SOCE and ER $\left[\mathrm{Ca}^{2+}\right]$ in primary larval neurons (Venkiteswaran and Hasan, 2009). Reduced SOCE has been shown to affect fly neuronal functions, in particular a significant loss of flight has been observed, accompanied by the loss of rhythmic flight patterns (Venkiteswaran and Hasan, 2009), indicating that, in neurons, the replenishment of intracellular $\mathrm{Ca}^{2+}$ stores is required for Drosophila flight. We observed a similar defect in flight ability, tested in the cylinder drop assay, in flies expressing spastin ${ }^{\mathrm{K} 467 \mathrm{R}}$. This phenotype is specific, since dSERCA mutant flies, where stored $\mathrm{Ca}^{2+}$ is decreased but SOCE is increased, do not display flight defects (Banerjee et al., 2006; Venkiteswaran and Hasan, 2009).

We found that spastin ${ }^{\text {K467R }}$-induced MT stabilization causes a change in ER morphology, shifting ER sheets/tubules balance toward the formation of sheets. Interestingly, an accumulation of ER sheets has also been reported in mammalian cells upon treatment with MT-depolymerizing (Terasaki et al., 1986; Joensuu et al., 2014) as well as -stabilizing agents (Joensuu and Jokitalo, 2015), suggesting that ER morphology is similarly affected upon MT cytoskeleton disruption or hyper-stabilization.

It is widely assumed that the structural heterogeneity of the ER contributes to its functional compartmentalization. Despite the fact that a clear-cut attribution of function to either sheets or tubules has yet to be defined, tubules appear to perform some specific functions. The involvement of TAC-mediated movement on MT tips suggests that the regulated process of SOCE is allocated specifically to ER tubules. The data we obtained allow us to speculate that MT disorganization and SOCE impairment are causally linked by the alteration of ER morphology observed upon spastin ${ }^{\mathrm{K} 467 \mathrm{R}}$ expression in flies: MT hyperstabilization shifts the ER sheets/tubules balance in favor of ER sheets; this in turn affects SOCE, a specific ER function that relies on the physical movement of ER tubules toward the PM. However, MT dynamics itself is critical to generate pushing and pulling forces during polymerization and depolymerization, respectively (Inoué and Salmon, 1995) providing the force required for membrane movement that can result in membrane translocation from one point to another within the cell. For this reason, we cannot exclude that MT impairment per se is responsible for the observed reduction of SOCE.

Beneficial effects from treatments with vinblastine have been reported in flies expressing spastin ${ }^{\mathrm{K} 467 \mathrm{R}}$ (Orso et al., 2005). By recovering MT organization, vinblastine rescues NMJs morphology and function, together with fly viability and climbing defects (Orso et al., 2005). We demonstrate that vinblastine treatment is able to rescue also ER morphology, $\mathrm{Ca}^{2+}$ handling defects and flight ability, indicating that MT impairment is the earliest responsible for all the phenotypes observed. Notably, acute vinblastine treatment (40 min application on dissociated neurons) is sufficient to rescue SOCE and $\mathrm{ER} \mathrm{Ca}^{2+}$ content. Within this time-window, transcriptional activation is unlikely to occur, suggesting that the level of $\mathrm{Ca}^{2+}$ handling proteins, and in particular of the SOCE machinery, is expected to be unaltered and the defects observed are directly ascribable to a MT dynamics impairment.

Tubulin represents about $4 \%$ of total cellular proteins in many cultured cells, however it reaches $25 \%$ in the brain (Zhai and Borisy, 1994). In axons and dendrites, MTs serve as the major railways for organelles and other cargoes and dysfunctional MT scaffolding has been primarily associated with impaired transport. Neuronal functionalities, including learning and memory, are associated with the normal functioning 
of dendritic spines that could be compromised if organelles and proteins do not reach their proper location. In addition to this evident relationship between MT organization and neuronal function, our present work supports the idea that other fundamental cellular mechanism, namely ER shape and function, are affected by MT disorganization caused by mutant spastin expression. This is critically important considering that increasing evidence suggests the presence of a causative link between derangement of ER morphology/function and the pathogenesis of HSPs.

\section{DATA AVAILABILITY STATEMENT}

The datasets generated for this study are available on request to the corresponding author.

\section{AUTHOR CONTRIBUTIONS}

DP conceived the work. NV and RN performed the experiments. $\mathrm{NV}$ and NR analyzed the results. PP and AD contributed to the interpretation of the results. DP wrote the manuscript. DP and PP secured funding. All the authors revised the manuscript.

\section{REFERENCES}

Agrawal, T., and Hasan, G. (2015). Maturation of a central brain flight circuit in Drosophila requires Fz2/Ca2+ signaling. Elife 4:e07046. doi: 10.7554/eLife.07046.035

Banerjee, S. (2004). Loss of flight and associated neuronal rhythmicity in inositol 1,4,5-trisphosphate receptor mutants of Drosophila. J. Neurosci. 24, 7869-7878. doi: 10.1523/JNEUROSCI.0656-04.2004

Banerjee, S., Joshi, R., Venkiteswaran, G., Agrawal, N., Srikanth, S., Alam, F., et al. (2006). Compensation of inositol 1,4,5-trisphosphate receptor function by altering sarco-endoplasmic reticulum calcium atpase activity in the Drosophila flight circuit. J. Neurosci. 26, 8278-8288. doi: 10.1523/JNEUROSCI.1231-06.2006

Berridge, M. J. (1998). Neuronal calcium signaling. Neuron. 21, 13-26. doi: 10.1016/S0896-6273(00)80510-3

Borodinsky, L. N., and Spitzer, N. C. (2007). Activity-dependent neurotransmitterreceptor matching at the neuromuscular junction. Proc. Natl. Acad. Sci. U.S.A. 104, 335-340. doi: 10.1073/pnas.0607450104

Burbank, K. S., and Mitchison, T. J. (2006). Microtubule dynamic instability. Curr. Biol. 16, 1375-1478. doi: 10.1016/j.cub.2006.06.044

Butler, R., Wood, J. D., Landers, J. A., and Cunliffe, V. T. (2010). Genetic and chemical modulation of spastin-dependent axon outgrowth in zebrafish embryos indicates a role for impaired microtubule dynamics in hereditary spastic paraplegia. Dis. Model. Mech. 3, 743-751. doi: 10.1242/dmm.004002

Carrasco, S., and Meyer, T. (2011). STIM proteins and the endoplasmic reticulum-plasma membrane junctions. Annu. Rev. Biochem. 80, 973-1000. doi: 10.1146/annurev-biochem-061609-165311

Chakraborty, S., and Hasan, G. (2018). Store-operated Ca2+ entry in Drosophila primary neuronal cultures. Methods Mol. Biol. 1843, 125-136. doi: 10.1007/978-1-4939-8704-7_11

Chen, Y. F., Chen, L. H., and Shen, M. R. (2019). The distinct role of STIM1 and STIM2 in the regulation of store-operated Ca $2+$ entry and cellular function. J. Cell. Physiol. 234, 8727-8739. doi: 10.1002/jcp.27532

Chen, Y. T., Chen, Y. F., Chiu, W. T., Liu, K. Y., Liu, Y. L., Chang, J. Y., et al. (2013). Microtubule-associated histone deacetylase 6 supports the calcium store sensor STIM1 in mediating malignant cell behaviors. Cancer Res. 73, 4500-4509. doi: 10.1158/0008-5472.CAN-12-4127

\section{FUNDING}

This work was supported by the Ministry of Education, University and Research (MIUR) (PRIN 2017 to PP; fellowship to NV); University of Padua (SID 2019 to PP; BIRD 2017 to DP for fellowships to RN and NR; UNIPD funds for research equipment-2015); Fondazione Cassa di Risparmio di Padova e Rovigo (CARIPARO Foundation, Starting Grant 2015 to DP and PP); Fondazione Telethon (Grant 2019 GGP19304 to DP).

\section{ACKNOWLEDGMENTS}

We thank Tullio Pozzan and Cristina Fasolato for helpful advice and discussion and Riccardo Osello for help with fly work. Stocks obtained from the Bloomington Drosophila Stock Center (NIH P40OD018537) were used in this study.

\section{SUPPLEMENTARY MATERIAL}

The Supplementary Material for this article can be found online at: https://www.frontiersin.org/articles/10.3389/fphys. 2019.01544/full\#supplementary-material

Conde, C., and Cáceres, A. (2009). Microtubule assembly, organization and dynamics in axons and dendrites. Nat. Rev. Neurosci. 10, 319-332. doi: $10.1038 / \mathrm{nrn} 2631$

Dabora, S. L., and Sheetz, M. F. (1988). The microtubule-dependent formation of a tubulovesicular network with characteristics of the ER from cultured cell extracts. Cell. 54, 27-35. doi: 10.1016/0092-8674(88)90176-6

Desai, A., and Mitchison, T. J. (1997). Microtubule polymerization dynamics. Annu. Rev. Cell Dev. Biol. 13, 83-117. doi: 10.1146/annurev.cellbio.13.1.83

Dreier, L., and Rapoport, T. A. (2000). In vitro formation of the endoplasmic reticulum occurs independently of microtubules by a controlled fusion reaction. J. Cell Biol. 148, 883-898. doi: 10.1083/jcb.148.5.883

Errico, A., Ballabio, A., and Rugarli, E. I. (2002). Spastin, the protein mutated in autosomal dominant hereditary spastic paraplegia, is involved in microtubule dynamics. Hum. Mol. Genet. 11, 153-163. doi: 10.1093/hmg/11.2.153

Fasolato, C., Zottini, M., Clementi, E., Zacchetti, D., Meldolesi, J., and Pozzan, T. (1991). Intracellular Ca2+ pools in PC12 cells: three intracellular pools are distinguished by their turnover and mechanisms of $\mathrm{Ca} 2+$ accumulation, storage, and release. J. Biol. Chem. 266, 20159-20167.

Fassier, C., Tarrade, A., Peris, L., Courageot, S., Mailly, P., Dalard, C., et al. (2013). Microtubule-targeting drugs rescue axonal swellings in cortical neurons from spastin knockout mice. Dis. Model. Mech. 6, 72-83. doi: 10.1242/dmm.008946

Feske, S., Gwack, Y., Prakriya, M., Srikanth, S., Puppel, S. H., Tanasa, B., et al. (2006). A mutation in orail causes immune deficiency by abrogating CRAC channel function. Nature. 441, 179-185. doi: 10.1038/nature04702

Fink, J. K. (2013). Hereditary spastic paraplegia: clinico-pathologic features and emerging molecular mechanisms. Acta Neuropathol. 126, 307-328. doi: 10.1007/s00401-013-1115-8

Friedman, J. R., Webster, B. M., Mastronarde, D. N., Verhey, K. J., and Voeltz, G. K. (2010). ER sliding dynamics and ER-mitochondrial contacts occur on acetylated microtubules. J. Cell Biol. 190, 363-375. doi: 10.1083/jcb.200911024

Galán, C., Dionisio, N., Smani, T., Salido, G. M., and Rosado, J. A. (2011). The cytoskeleton plays a modulatory role in the association between STIM1 and the Ca2+ channel subunits Orail and TRPC1. Biochem. Pharmacol. 82, 400-410. doi: 10.1016/j.bcp.2011.05.017

Grigoriev, I., Gouveia, S. M., van der Vaart, B., Demmers, J., Smyth, J. T., Honnappa, S., et al. (2008). STIM1 is a MT-plus-end-tracking protein involved in remodeling of the ER. Curr. Biol. 18, 177-182. doi: 10.1016/j.cub.2007.12.050 
Gurel, P. S., Hatch, A. L., and Higgs, H. N. (2014). Connecting the cytoskeleton to the endoplasmic reticulum and Golgi. Curr. Biol. 24, R660-R672. doi: 10.1016/j.cub.2014.05.033

Harkcom, W. T., Ghosh, A. K., Sung, M. S., Matov, A., Brown, K. D., Giannakakou, P., et al. (2014). NAD+ and SIRT3 control microtubule dynamics and reduce susceptibility to antimicrotubule agents. Proc. Natl. Acad. Sci. U.S.A. 111, E2443-E2452. doi: 10.1073/pnas.1404269111

Hazan, J., Fonknechten, N., Mavel, D., Paternotte, C., Samson, D., Artiguenave, F., et al. (1999). Spastin, a new AAA protein, is altered in the most frequent form of autosomal dominant spastic paraplegia. Nat. Genet. 23, 296-303. doi: $10.1038 / 15472$

Honnappa, S., Gouveia, S. M., Weisbrich, A., Damberger, F. F., Bhavesh, N. S., Jawhari, H., et al. (2009). An EB1-binding motif acts as a microtubule tip localization signal. Cell. 138, 366-376. doi: 10.1016/j.cell.2009.04.065

Inoué, S., and Salmon, E. D. (1995). Force generation by microtubule assembly/disassembly in mitosis and related movements. Mol. Biol. Cell 6, 1619-1640. doi: 10.1091/mbc.6.12.1619

Joensuu, M., Belevich, I., Rämö, O., Nevzorov, I., Vihinen, H., Puhka, M., et al. (2014). ER sheet persistence is coupled to myosin 1c-regulated dynamic actin filament arrays. Mol. Biol. Cell. 25, 1111-1126. doi: 10.1091/mbc.e13-12-0712

Joensuu, M., and Jokitalo, E. (2015). ER sheet-tubule balance is regulated by an array of actin filaments and microtubules. Exp. Cell Res. 337, 170-178. doi: $10.1016 /$ j.yexcr.2015.04.009

Kapitein, L. C., and Hoogenraad, C. C. (2015). Building the neuronal microtubule cytoskeleton. Neuron 87, 492-506. doi: 10.1016/j.neuron.2015.05.046

Kasher, P. R., De Vos, K. J., Wharton, S. B., Manser, C., Bennett, E. J., Bingley, M., et al. (2009). Direct evidence for axonal transport defects in a novel mouse model of mutant spastin-induced hereditary spastic paraplegia (HSP) and human HSP patients. J. Neurochem. 110, 34-44. doi: $10.1111 / j .1471-4159.2009 .06104 . x$

Kirschner, M., and Mitchison, T. (1986). Beyond self-assembly: from microtubules to morphogenesis. Cell. 45, 329-342. doi: 10.1016/0092-8674(86)90318-1

Krijnse-Locker, J., Parton, R. G., Fuller, S. D., Griffiths, G., and Dotti, C. G. (1995). The organization of the endoplasmic reticulum and the intermediate compartment in cultured rat hippocampal neurons. Mol. Biol. Cell. 6, 1315-1332. doi: $10.1091 / \mathrm{mbc} .6 .10 .1315$

Lee, C., and Chen, L. B. (1988). Dynamic behavior of endoplasmic reticulum in living cells. Cell. 54, 37-46. doi: 10.1016/0092-8674(88)90177-8

Liou, J., Fivaz, M., Inoue, T., and Meyer, T. (2007). Live-cell imaging reveals sequential oligomerization and local plasma membrane targeting of stromal interaction molecule 1 after Ca2+ store depletion. Proc. Natl. Acad. Sci. U.S.A. 104, 9301-9306. doi: 10.1073/pnas.0702866104

Liou, J., Kim, M. L., Won, D. H., Jones, J. T., Myers, J. W., Ferrell, J. E., et al. (2005). STIM is a Ca2+ sensor essential for Ca2+-store- depletiontriggered Ca2+ influx. Curr. Biol. 15, 1235-1241. doi: 10.1016/j.cub.2005. 05.055

Lissandron, V., Podini, P., Pizzo, P., and Pozzan, T. (2010). Unique characteristics of Ca2+ homeostasis of the trans-Golgi compartment. Proc. Natl. Acad. Sci. U.S.A. 107, 9198-9203. doi: 10.1073/pnas.1004702107

Lu, L., Ladinsky, M. S., and Kirchhausen, T. (2009). Cisternal organization of the endoplasmic reticulum during mitosis. Mol. Biol. Cell. 20, 3471-3480. doi: 10.1091/mbc.e09-04-0327

Luik, R. M., Wang, B., Prakriya, M., Wu, M. M., and Lewis, R. S. (2008). Oligomerization of STIM1 couples ER calcium depletion to CRAC channel activation. Nature 454, 538-542. doi: 10.1038/nature07065

Maléth, J., Choi, S., Muallem, S., and Ahuja, M. (2014). Translocation between PI(4,5)P 2 -poor and PI(4,5)P 2 -rich microdomains during store depletion determines STIM1 conformation and Orail gating. Nat. Commun. 5:5843. doi: $10.1038 /$ ncomms6843

Martin-Romero, F. J., Lopez-Guerrero, A. M., Pascual-Caro, C., and PozoGuisado, E. (2017). "The interplay between cytoskeleton and calcium dynamics," in Cytoskeleton - Structure, Dynamics, Function and Disease, ed J. C. Jimenez-Lopez (London: IntechOpen). doi: 10.5772/66862

Nogales, E. (2001). Structural insights into microtubule function. Annu. Rev. Biochem. 69, 277-302. doi: 10.1146/annurev.biochem.69.1.277

Oka, T., Hori, M., and Ozaki, H. (2005). Microtubule disruption suppresses allergic response through the inhibition of calcium influx in the mast cell degranulation pathway. J. Immunol. 174, 4584-459. doi: 10.4049/jimmunol.174.8.4584
Orso, G., Martinuzzi, A., Rossetto, M. G., Sartori, E., Feany, M., and Daga, A. (2005). Disease-related phenotypes in a Drosophila model of hereditary spastic paraplegia are ameliorated by treatment with vinblastine. J. Clin. Invest. 115, 3026-3034. doi: 10.1172/JCI24694

Orso, G., Pendin, D., Liu, S., Tosetto, J., Moss, T. J., Faust, J. E., et al. (2009). Homotypic fusion of ER membranes requires the dynamin-like GTPase atlastin. Nature 460, 978-983. doi: 10.1038/nature08280

Pendin, D., Greotti, E., Lefkimmiatis, K., and Pozzan, T. (2017). Exploring cells with targeted biosensors. J. Gen. Physiol. 149, 1-36. doi: 10.1085/jgp.201611654

Penner, R., Fasolato, C., and Hoth, M. (1993). Calcium influx and its control by calcium release. Curr. Opin. Neurobiol. 3, 368-374. doi: 10.1016/0959-4388(93)90130-Q

Prakriya, M., Feske, S., Gwack, Y., Srikanth, S., Rao, A., and Hogan, P. G. (2006). Orail is an essential pore subunit of the CRAC channel. Nature. 443, 230-233. doi: 10.1038 /nature 05122

Puhka, M., Joensuu, M., Vihinen, H., Belevich, I., and Jokitalo, E. (2012). Progressive sheet-to-tubule transformation is a general mechanism for endoplasmic reticulum partitioning in dividing mammalian cells. Mol. Biol. Cell. 23, 2424-2432. doi: 10.1091/mbc.e10-12-0950

Redondo, P. C., Harper, M. T., Rosado, J. A., and Sage, S. O. (2006). A role for cofilin in the activation of store-operated calcium entry by de novo conformational coupling in human platelets. Blood 107, 973-979. doi: 10.1182/blood-2005-05-2015

Roll-Mecak, A., and McNally, F. J. (2010). Microtubule-severing enzymes. Curr. Opin. Cell Biol. 22, 96-103. doi: 10.1016/j.ceb.2009.11.001

Russa, A. D., Ishikita, N., Masu, K., Akutsu, H., Saino, T., and Satoh, Y. (2009). Microtubule remodeling mediates the inhibition of store-operated calcium entry (SOCE) during mitosis in COS-7 cells. Arch. Histol. Cytol. 71, 249-263. doi: 10.1679/aohc.71.249

Sandate, C. R., Szyk, A., Zehr, E. A., Lander, G. C., and Roll-Mecak, A. (2019). An allosteric network in spastin couples multiple activities required for microtubule severing. Nat. Struct. Mol. Biol. 26, 671-678. doi: 10.1038/s41594-019-0257-3

Secondo, A., Bagetta, G., and Amantea, D. (2018). On the role of store-operated calcium entry in acute and chronic neurodegenerative diseases. Front. Mol. Neurosci. 11:87. doi: 10.3389/fnmol.2018.00087

Sharma, S., Quintana, A., Findlay, G. M., Mettlen, M., Baust, B., Jain, M., et al. (2013). An siRNA screen for NFAT activation identifies septins as coordinators of store-operated Ca2+ entry. Nature 499, 238-242. doi: 10.1038/nature12229

Sharp, D. J., and Ross, J. L. (2012). Microtubule-severing enzymes at the cutting edge. J. Cell Sci. 125(Pt. 11), 2561-2569. doi: 10.1242/jcs.101139

Sherwood, N. T., Sun, Q., Xue, M., Zhang, B., and Zinn, K. (2004). Drosophila spastin regulates synaptic microtubule networks and is required for normal motor function. PLoS Biol. 2:e429. doi: 10.1371/journal.pbio.0020429

Smyth, J. T., DeHaven, W. I., Bird, G. S., and Putney, J. W. (2007). Role of the microtubule cytoskeleton in the function of the store-operated Ca2 + channel activator STIM1. J. Cell Sci. 120(Pt. 21), 3762-3771. doi: 10.1242/jcs.015735

Soboloff, J., Rothberg, B. S., Madesh, M., and Gill, D. L. (2012). STIM proteins: dynamic calcium signal transducers. Nat. Rev. Mol. Cell Biol. 13, 549-565. doi: $10.1038 / \mathrm{nrm} 3414$

Summerville, J. B., Faust, J. F., Fan, E., Pendin, D., Daga, A., Formella, J., et al. (2016). The effects of ER morphology on synaptic structure and function in Drosophila melanogaster. J. Cell Sci. 129, 1635-1648. doi: 10.1242/jcs.184929

Terasaki, M. (2018). Axonal endoplasmic reticulum is very narrow. J. Cell Sci. 131:210450. doi: 10.1242/jcs.210450

Terasaki, M., Chen, L. B., and Fujiwara, K. (1986). Microtubules and the endoplasmic reticulum are highly interdependent structures. J. Cell Biol. 103, 1557-1568. doi: 10.1083/jcb.103.4.1557

Terasaki, M., and Reese, T. S. (1994). Interactions among endoplasmic reticulum, microtubules, and retrograde movements of the cell surface. Cell Motil. Cytoskeleton. 29, 291-300. doi: 10.1002/cm.970290402

Trotta, N., Orso, G., Rossetto, M. G., Daga, A., and Broadie, K. (2004). The hereditary spastic paraplegia gene, spastin, regulates microtubule stability to modulate synaptic structure and function. Curr. Biol. 14, 1135-1147. doi: 10.1016/j.cub.2004.06.058

Tsai, F. C., Seki, A., Yang, H. W., Hayer, A., Carrasco, S., Malmersjö, S., et al. (2014). A polarized Ca2+, diacylglycerol and STIM1 signalling system regulates directed cell migration. Nat. Cell Biol. 16, 133-144. doi: 10.1038/ncb2906 
Tsukita, S., and Ishikawa, H. (1976). Three-dimensional distributionof smooth endoplasmic reticulum in myelinated axons. J. Electron Microsc. 25, 141-149.

Várnai, P., Hunyady, L., and Balla, T. (2009). STIM and orai: the long-awaited constituents of store-operated calcium entry. Trends Pharmacol. Sci. 30, 118-128. doi: 10.1016/j.tips.2008.11.005

Venkiteswaran, G., and Hasan, G. (2009). Intracellular Ca2+ signaling and storeoperated $\mathrm{Ca} 2+$ entry are required in Drosophila neurons for flight. Proc. Natl. Acad. Sci. U.S.A. 106, 10326-10331. doi: 10.1073/pnas.0902982106

Vig, M., Beck, A., Billingsley, J. M., Lis, A., Parvez, S., Peinelt, C., et al. (2006a). CRACM1 multimers form the ion-selective pore of the CRAC channel. Curr. Biol. 16, 2073-2079. doi: 10.1016/j.cub.2006.08.085

Vig, M., Peinelt, C., Beck, A., Koomoa, D. L., Rabah, D., Koblan-Huberson, M., et al. (2006b). CRACM1 is a plasma membrane protein essential for storeoperated Ca 2+ entry. Science 312, 1220-1223. doi: 10.1126/science.1127883

Waterman-Storer, C. M., and Salmon, E. D. (1998). Endoplasmic reticulum membrane tubules are distributed by microtubules in living cells using three distinct mechanisms. Curr. Biol. 8, 798-807. doi: 10.1016/S0960-9822(98)70321-5

Wong, A. K. C., Capitanio, P., Lissandron, V., Bortolozzi, M., Pozzan, T., and Pizzo, P. (2013). Heterogeneity of Ca2+ handling among and within Golgi compartments. J. Mol. Cell Biol. 5, 266-276. doi: 10.1093/jmcb/ mjt024

Woo, J. S., Srikanth, S., Nishi, M., Ping, P., Takeshima, H., and Gwack, Y. (2016). Junctophilin-4, a component of the endoplasmic reticulum-plasma membrane junctions, regulates Ca $2+$ dynamics in T cells . Proc. Natl. Acad. Sci. U.S.A. 113, 2762-2767. doi: 10.1073/pnas. 1524229113

Wood, J. D., Landers, J. A., Bingley, M., McDermott, C. J., Thomas-McArthur, V., Gleadall, L. J., et al. (2006). The microtubule-severing protein Spastin is essential for axon outgrowth in the zebrafish embryo. Hum. Mol. Genet. 15, 2763-2771. doi: 10.1093/hmg/ddl212

Wu, M. M., Buchanan, J., Luik, R. M., and Lewis, R. S. (2006). Ca 2+ store depletion causes STIM1 to accumulate in ER regions closely associated with the plasma membrane. J. Cell Biol. 174, 803-813. doi: 10.1083/jcb.200604014
Yeromin, A. V., Zhang, S. L., Jiang, W., Yu, Y., Safrina, O., and Cahalan, M. D. (2006). Molecular identification of the CRAC channel by altered ion selectivity in a mutant of Orai. Nature 443, 226-229. doi: 10.1038/nature05108

Yu, W., Qiang, L., Solowska, J. M., Karabay, A., Korulu, S., and Baas, P. W. (2008). The microtubule-severing proteins spastin and katanin participate differently in the formation of axonal branches. Mol. Biol. Cell. 19, 1485-1498. doi: 10.1091/mbc.e07-09-0878

Zampese, E., and Pizzo, P. (2012). Intracellular organelles in the saga of $\mathrm{Ca} 2+$ homeostasis: different molecules for different purposes? Cell. Mol. Life Sci. 69, 1077-1104. doi: 10.1007/s00018-011-0845-9

Zhai, Y., and Borisy, G. G. (1994). Quantitative determination of the proportion of microtubule polymer present during the mitosis-interphase transition. J. Cell Sci. 107(Pt. 4), 881-890.

Zhang, S. L., Yeromin, A. V., Zhang, X. H.-F., Yu, Y., Safrina, O., Penna, A., et al. (2006). Genome-wide RNAi screen of Ca2+ influx identifies genes that regulate Ca2+ release-activated Ca2+ channel activity. Proc. Natl. Acad. Sci. U.S.A. 103, 9357-9362. doi: 10.1073/pnas.0603161103

Zhang, S. L., Yu, Y., Roos, J., Kozak, J. A., Deerinck, T. J., Ellisman, M. H., et al. (2005). STIM1 is a Ca2 + sensor that activates CRAC channels and migrates from the Ca2+ store to the plasma membrane. Nature 437, 902-905. doi: 10.1038 /nature 04147

Conflict of Interest: The authors declare that the research was conducted in the absence of any commercial or financial relationships that could be construed as a potential conflict of interest.

Copyright (c) 2019 Vajente, Norante, Redolfi, Daga, Pizzo and Pendin. This is an open-access article distributed under the terms of the Creative Commons Attribution License (CC BY). The use, distribution or reproduction in other forums is permitted, provided the original author(s) and the copyright owner(s) are credited and that the original publication in this journal is cited, in accordance with accepted academic practice. No use, distribution or reproduction is permitted which does not comply with these terms. 